\title{
Explaining Cross-Racial Differences in Teenage Labor Force Participation: Results from a General Equilibrium Search Model
}

\author{
Peter Arcidiacono* Alvin Murphy Omari Swinton \\ Duke University Duke University Duke University \\ June 14, 2005
}

\begin{abstract}
White teenagers are substantially more likely to search for employment than their black counterparts. This occurs despite the fact that conditional on race individuals who come from poorer families are more likely to search and black teenagers come from poorer families. While differences in wages between white and black teenagers are small, the unemployment rate for black teenagers is over twice that of white teenagers. We develop a general equilibrium search model where firms are partially able to target their search based upon demographics. Differences in the labor market explain half of the gap in the search rates between black and white teenagers. Removing search targeting substantially closes the gap between black and white unemployment rates.
\end{abstract}

\section{Introduction}

The teenage labor force participation rate for whites during the school year was a little over $50 \%$ in the nineties. The corresponding number for blacks

*Department of Economics, Duke University Box 90097, Durham, NC 27708. Phone: 919660-1816. Psarcidi@econ.duke.edu. 
is much smaller at $35 \%$. The lower labor force participation rate for black teenagers is surprising given that black teenagers on average come from poorer and less educated families, groups that typically have higher teenage labor force participation rates. We estimate a general equilibrium search model to separate out how much the differences in labor force participation rates result from different tastes for work, differences in productivity and discrimination at the wage setting stage, and differences in search rates by firms.

The potential for search discrimination to play a large role in differences in labor force participation rates follows from the much higher probabilities white teenagers have of finding work conditional on searching. Data from the Current Population Survey show that from 1989-2000 the average probability of a white teenager finding a job was over $86 \%$ while the corresponding probability for a black teenager was less than 70\%. Indeed, data from recent audit studies show that even having a black sounding name on your resume can result in a lower probability of being called in for an interview. Discrimination by searching firms can then have a magnified effect on labor market outcomes through lowering the search rates of the discriminated group.

While some theoretical work exists showing how search discrimination may lead to cross-racial differences in outcomes, empirical estimates of search models with discrimination are few. This is in part because search models have generally focused on infinite horizon models with identical individuals having a steady state reservation wage. These models are particularly cumbersome to work with and are clearly inappropriate for studies of teenage labor supply. In fact, few papers even estimate the elasticity of teenage labor supply in general, let alone across races.

For these reasons, we focus on extending the model used by Ahn and Arcidiacono (2005). There, individuals and firms match through a one shot game where both the labor supply of workers and the search rates of firms are endogenous and the employment level is determined by a matching function. Matched firms and workers then negotiate over the wage using generalized Nash bargaining. By having the search process over in one step, it is possible to make 
other parts of the model much more complicated. For example, it is easy to incorporate both endogenous labor supply and endogenous firm vacancies. The latter results from zero expected profits from posting a vacancy while the former results from workers having heterogeneous values of leisure.

A key contribution of our paper is that firms are partially able to target their search through choosing different search methods. For example, advertising vacancies through one medium may lead to a higher probability of matching with a white worker than with a black worker. Since firms are identical, expected zero profit conditions must hold across search methods. With black-white productivity gaps varying across locations as well as location-specific minimum wages, firms in different locations have differing incentives to target their search.

There is then a separate matching function for each search method. Whites and blacks know their probabilities of being placed in each of the matching functions and use this information in forming their decision as to whether to search. In equilibrium, firms know the number of searching workers and associated racial distributions for each of the matching functions in forming their decisions as to which method to use to post a vacancy.

In practice we do not observe the different matching functions. However, we can integrate out the probabilities of blacks and whites matching in particular markets using mixture distributions. The key features in the data which identify the distributions of blacks and whites associated with particular matching functions in particular locations are 1) the probabilities of finding a match conditional on searching, 2) how these probabilities feed into the probabilities of searching, and 3) the productivity gap and minimum wage laws in the location. This empirical strategy can be extended to multiple search methods on multiple features of the individual. For example, firms may be interested in targeting their search to those who come from wealthier or more educated families because of the ex ante higher expected productivity for those individuals.

The data we use to estimate the model comes from a twelve year band of the basic monthly outgoing rotation files of the Current Population Survey (CPS) from 1989 to 2000. We use black and white teenagers from 16 to 19 
years old during non summer months whose primary residence is in the home of their parents. We focus on North Carolina because of the relatively large sample of black teenagers. The data contain hourly wages, employment status and whether the individual was looking for work. Demographic characteristics such as parental marital status and parental income are used to approximate the reservation wage.

Estimates of the model show that productivity differs significantly by race and age. However, firms are more able to target their search based upon race than based upon age. Indeed, the raw data show that black nineteen year olds earn substantially more than white sixteen year olds, yet their unemployment rates are much higher. Differences in the labor market for black workers is then shown to explain half of the difference between black and white labor force participate rates.

We use the estimates of the model to simulate how removing targeted search affects the labor market outcomes for blacks and whites. Removing the targeting breaks a large portion of the tie between race and unemployment, with some gap remaining due to the average value of a match being lower with a black teenager than with a white teenager. Lower match values for blacks means pooling blacks with whites leads to higher unemployment rates for whites. This leads to a feedback effect in that whites respond to the higher unemployment rates by searching less often.

The rest of the paper proceeds as follows. Section 2 discusses the related literature. Section 3 proposes the model. Section 4 describes the data while section 5 shows how the data can be used to structurally estimate the model. Results are presented in section 6 with policy simulations conducted in section 7. Section 8 concludes.

\section{Related Literature}

Alternative models to the classical model for low wage labor markets have received more attention recently due in part to the findings of Card and Krueger 
(1994, 1995). Their research, although heavily criticized, ${ }^{1}$ points towards changes in employment levels due to minimum wage changes possibly not measuring labor demand elasticities. Search models allow other factors to impact the effect of a minimum wage on employment levels besides through labor demand. In addition to Ahn and Arcidiacono (2005), Lang and Kahn (1998), Flinn (2003), and van den Berg (2003) examine search models in the presence of a minimum wage. The latter two papers are in the spirit of the traditional search literature $^{2}$ where workers solve dynamic optimization problems in determining their reservation wages but must trade off having firms earn positive profits and not dealing with heterogeneity in leisure values affecting the labor supply decision.

One of the distinguishing features of our model is that it allows firms to partially target their search for different types of workers based on observable characteristics. Previous literature has focused on models where either perfect targeting or no targeting of different workers types is possible. Black (1995) proposes a theoretical search model where firms can perfectly target their search. Firms are heterogeneous with the marginal discriminatory and non-discriminatory firms earning zero profits in equilibrium. Bowlus and Eckstein (2002) allows for perfect targeting that is similar to Black (1995) but provide estimates of a model where firms earn positive profits. In their paper, firms can make wage offers conditional on worker type, which allows workers to be treated as if they come from different markets. Sattinger (1998) presents two theoretical models. One model allows for "active" recruitment or perfect targeting whereby firms can choose which type of workers to interview. The least attractive group of workers will receive less interviews and face higher unemployment. In his alternative model firms are "passive" recruiters who can not target their search. As a result high ability workers are hurt by firms' inability to separate them from low ability workers.

The treatment of unemployment and minimum wages is similar to work by Meyer and Wise (1983a, 1983b). Meyer and Wise assume that workers fall

\footnotetext{
${ }^{1}$ See for example, Neumark and Wachter (2000).

${ }^{2}$ See Eckstein and van den Berg (forthcoming) for a review.
} 
into four categories:unemployed, employed at less than the minimum wage, employed at the minimum wage, and employed above the minimum wage. Therefore, the density of the wage distribution is reduced at all points below the minimum wage and a spike in the distribution of wages occurs at the minimum. The primary difference here is that our model comes from firms and workers solving their respective optimization problems at the expense of ignoring workers who earn less than the minimum wage.

\section{Model}

In this section we present a two-sided search model similar to Ahn and Arcidiacono (2005). The key extension is that firms are able to partially target their search based upon observable characteristics: in Ahn and Arcidiacono either full targeting occurred (separate labor markets) or no targeting was possible. We assume that there are $K$ types of workers where $k$ indexes type. Each worker is a member of only one type. Let $\bar{N}_{k}$ index the number of type $k$ individuals in the population. The number of workers of each type who search is endogenous as is the number of searching firms, $J$. Let $N_{k}$ indicate the number of searching workers of type $k$.

The different types of workers may differ in their average productivity and their attachment to the labor force. Firms then have an incentive to target their search. We assume that firms are able to at least partially target their search through their choice of one of $M$ search methods where $m$ indexes the method. $J_{m}$ then indexes the number of searching firms who choose method $m$.

Workers and firms are matched using a Cobb-Douglas matching function for each search method with the restriction that the number of matches can be no greater than either the number of searching workers or the number of searching firms. Let $x_{m}$ index the number of matches produced by method $m$ and is given by:

$$
x_{m}=\min \left\{A J_{m}^{\alpha} N_{m}^{1-\alpha}, J_{m}, N_{m}\right\}
$$


While individuals choose to search, they do not control by which method a job offer will be obtained. Rather, $\lambda_{m k}$, the probability of being assigned to method $m$ conditional on being the $k$ th type, is taken as exogenous. The number of workers assigned to method $m$ is then given by:

$$
N_{m}=\sum_{k=1}^{K} \lambda_{m k} N_{k}
$$

and $\sum_{m=1}^{M} \lambda_{m k}=1$ for all $k$.

We assume that, conditional on being assigned to a particular method, all workers have the same probability of being matched, $p_{m}=x_{m} / N_{m}$. With workers only knowing the probabilities of being assigned to particular methods, the probability of a worker with type $k$ matching with a firm is given by:

$$
p_{k}=\sum_{m=1}^{M} \lambda_{m k} p_{m}
$$

Firms who search using a particular method also have identical probabilities of matching, $q_{m}=x_{m} / J_{m}$. Further, firms using the same method also have identical probabilities of matching with a particular type of worker. The probability of matching with a worker of type $k$ using method $m$ is then:

$$
q_{m k}=q_{m} \Lambda_{m k}
$$

where $\Lambda_{m r}$ is given by:

$$
\Lambda_{m k}=\frac{\lambda_{m k} N_{k}}{\sum_{k^{\prime}=1}^{K} \lambda_{m k^{\prime}} N_{k^{\prime}}}
$$

Individuals are differentiated in their reservation values for not working. The $i$ th individual of type $k$ has reservation value $R_{i k}$, where $R_{i k}$ is drawn from the cumulative distribution function $F_{k}(R)$ and has support $[0, \infty)$ This reservation value can be leisure or any outside option for workers. For instance, we may assume that $R_{i k}$ is the value of schooling for teenagers, with the treatment effect of education varying across the population and across type.

Denote $C_{1}$ as the search cost which is uniform across individuals and is paid whether an individual matches with a firm or not. Individuals are risk neutral 
and the the net expected value of searching for individual $i$ of type $k, V_{i k}$, is given by:

$$
V_{i k}=p_{k} E \max \left\{W-R_{i k}, 0\right\}-C_{1},
$$

where $W$ is the wage. Individuals search when $V_{i k}>0$.

The number of firms using method $m$ to search for workers, $J_{m}$, is endogenous. Production from a match is given by $S$ and, like workers, firms pay a search cost, $C_{2}$, whether or not they find a match. Firms enter until all firms have zero expected profits in each search method. Expected profits for searching using method $m$ are then given by:

$$
\sum_{k=1}^{K} q_{m k} E\left(\max \left\{S_{k}-W_{k}, 0\right\}\right)-C_{2}=0 .
$$

as firms will reject matches where $S<W$. We assume that the surplus of the match is match-specific and is given by $S_{i j k}$ where $S_{i j k}$ is drawn from the cumulative distribution function $G_{k}(S)$, and has support $[\underline{S}, \bar{S}]$.

We now specify the wage-generating process. Matched pairs split $S$ according to generalized Nash bargaining, with the caveat that a successful match pays at least the minimum wage, $\underline{W} .{ }^{3}$ The worker's bargaining power is set at $\beta, \beta \in(0,1)$. Wages for a successful match are then given by:

$$
W_{i j k}=\max \left\{\beta S_{i j k}, \underline{W}\right\} .
$$

with the wages of unsuccessful matches set at zero. The splitting of the surplus in this manner can generate the spike observed at the minimum wage in the data. All matches where the worker's share of the surplus would normally be below the minimum wage will earn the same wage even if their match-specific components differ.

Contrary to the standard search literature but similar to Ahn and Arcidiacono, the reservation value has no effect on the wage. This is because reservation values here are not the future value of search but the value of leisure which is not verifiable and generally not something workers want to send positive signals

\footnotetext{
${ }^{3}$ See Flinn (2003) for a similar specification.
} 
about. With reservation values not affecting the bargaining process it may be possible to have matches with excess surplus that are rejected by the worker. Let $\epsilon_{A}$ give the expected value of $\epsilon$ conditional on a match being acceptable and let $\pi_{A}$ be the corresponding probability of an acceptable match conditional on matching. We make the same assumption as in Ahn and Arcidiacono which ensures that all matches are acceptable to workers:

$$
\text { A.1 } \pi_{A} \beta\left(S_{A}-\underline{S}\right)<C_{1} \text { for all }\left\{\pi_{A}, S_{A}\right\}
$$

The model has a number of implications. First, consider the case where firms can perfectly target their search. In order for the zero profit condition to hold, workers from groups where the expected value of the surplus is high will then have higher probabilities of finding a match. These higher probabilities of finding a match then feedback into higher probabilities of looking for a job. Hence, groups with high surplus levels have higher employment levels both because demand is greater but also because of the decisions as to whether to participate in the labor market.

As firms become less able to target their search, those from groups with low surplus values benefit. Because they are pooled with groups with higher surplus values, demand is higher. In contrast, those groups with higher surplus values are hurt as targeting decreases because they are begin pooled with groups with low surplus values. This effect is magnified with endogenous labor supply. By partially removing targeting, members of the groups with high surplus values become less likely to participate while members of groups with low surplus values become more likely to participate. These effects further lower the equilibrium probabilities of both groups finding employment.

The size of the groups also matter. If groups with low surplus values are relatively small, they will have little impact on the labor market outcomes of those groups with high surplus values. As long as there is targeting is not perfect, groups with low surplus values prefer to be severely outnumbered by those from groups with high surplus values. 


\section{Data}

In this section, we present the data we use. We use twelve years of the basic monthly outgoing rotation groups, (ORG) survey files of the Current Population Survey (CPS) from 1989 to 2000. The CPS ORG is ideal for our estimation as the hourly wage variable is obtained from direct reports of hourly wages. We use black and white teenager workers ages 16 to 19 during non summer months to look for discrimination at the searching stage. These teenagers are matched with their parents to obtain household characteristics. The sample then contains data only on teenagers that still live in their parents' household.

From the CPS, we collect hourly wage, the individuals' employment status, whether the individual is looking for work, and demographic characteristics such as parental weekly income, and whether the teenager comes from a single parent home. All income variables are adjusted to 2000 dollars using the CPI. To correct for misreporting of the hourly wages, if a teenagers' reported wage is below the minimum wage but within twenty-five cents, we attribute the minimum wage to them. Teenagers, who report an hourly wage more than twenty-five cents below the minimum wage, and those who report being employed but do not report an hourly wage, are excluded from our sample.

We focus our analysis on data from North Carolina. This is because we need enough blacks in a particular labor market so that when we calculate the probability of a firm matching with a particular type of worker it will closely reflect the samples from the CPS. Table 1 gives descriptive statistics by race for three groups of North Carolina teenagers: the entire sample, those who are classified as searchers, and those who are employed. Since matching is the result of a one-shot game, searchers are both the unemployed plus the employed, with the employed being those who successfully matched.

Particularly relevant for the teenage labor market is the minimum wage. As with the rest of the southern states, the binding minimum wage is the federal minimum wage. In nominal terms, the minimum wage was $\$ 3.35$ in 1989 . The federal minimum wage increased to $\$ 3.80$ April 1st, 1990 and increased again on 
April 1st, 1991 to $\$ 4.25$. The minimum wage was increased again on October 1st, 1996 to $\$ 4.75$, with the final minimum wage change over the sample period occurring on September 1st, 1997 to $\$ 5.15$.

The full North Carolina sample shows that blacks are two and a half times more likely to come from a single parent family, with slightly less than half of blacks in the sample coming from a single parent family. Conditional on reporting parents reporting weekly income, parents of black teenagers make sixty-three percent of the amount of their white counterparts. Blacks and whites are equally likely to not report parental income, but for very different reasons. Almost fifteen percent of white households report that the father is employed but do not report his income. The corresponding number for blacks is less than four percent. In contrast, black households do not report income because there is no individual working over sixteen percent of the time. The corresponding number for whites is a little over five percent.

The most surprising feature of the descriptive statistics are that blacks are thirty percent less likely to be in the labor force than their white counterparts. Given that black teenagers are coming from worse family situations, we would suspect that black teenagers would be more likely to search than whites. The fact that is not so is suggestive that blacks are facing substantially different labor markets than their whites.

Support for the black teenage labor market being different from the white teenage labor market can be found in the second column of Table 1 where the descriptive statistics are reported for searching workers. ${ }^{4}$ Here we see that blacks have unemployment rates that are almost two and a half times those of whites. Conditional on race, we also see that individuals who come from single parent families and who have lower household incomes are more likely to participate in the labor market.

The third column of Table 1 examines the characteristics of those who were able to find work. Here we see that wages for blacks are lower than their white

\footnotetext{
${ }^{4}$ Recall that searching workers refers to both the employed and those who report looking for work.
} 
counterparts with whites earning about four per cent (twenty-five cents an hour) more than blacks. However, this four percent difference is small relative to the large differences in employment rates.

Table 1: Sample Statistics for North Carolina by Race

\begin{tabular}{lcccccc}
\hline \hline & \multicolumn{2}{c}{ Entire Sample } & \multicolumn{2}{c}{ Searching } & \multicolumn{2}{c}{ Employed } \\
& Black & White & Black & White & Black & White \\
\hline Age & 17.32 & 17.34 & 17.68 & 17.51 & 17.75 & 17.53 \\
& $(1.10)$ & $(1.07)$ & $(1.07)$ & $(1.06)$ & $(1.05)$ & $(1.06)$ \\
Weekly Parent Income (\$) & 562 & 890 & 561 & 839 & 587 & 845 \\
& $(441)$ & $(587)$ & $(448)$ & $(540)$ & $(464)$ & $(541)$ \\
Parent Income Not Reported & 0.037 & 0.149 & 0.030 & 0.134 & 0.033 & 0.137 \\
Parent Not Working & 0.163 & 0.053 & 0.140 & 0.049 & 0.105 & 0.044 \\
Female & 0.455 & 0.463 & 0.435 & 0.443 & 0.473 & 0.442 \\
Single Parent & 0.483 & 0.184 & 0.494 & 0.194 & 0.482 & 0.188 \\
Pr(Search) & 0.354 & 0.503 & & & & \\
Pr(Emp | Search) & & & 0.720 & 0.885 & & \\
Hourly Wage & & & & & 5.94 & 6.19 \\
& & & & & & \\
\end{tabular}

To investigate the differences in employment outcomes in more detail, Table 2 breaks out the descriptive statistics by age. White teenagers are more likely to search as age is increased and this may be because of better labor market outcomes due to increases in their own skill level. Unemployment rates are fiftypercent higher for sixteen year old whites than nineteen year old whites. Sixteen year old whites who do find jobs are over three and a half times more likely to be right at the minimum wage than their nineteen year old counterparts, with 
nineteen year old whites having average wages conditional on employment that are $\$ 1.50$ higher than sixteen year olds.

Similar age trends are seen for blacks. Nineteen year old blacks are almost two and a half times likely to be in the labor market than sixteen year old blacks. Conditional on finding a job, sixteen year old blacks are over three times as likely to be at the minimum wage and earn on average over a dollar less than nineteen year old blacks.

The most striking feature of Table 2, however, are comparing across races. Table 2 debunks the notion that the differences in employment rates are driven solely by differences in productivity by blacks and whites. Nineteen year old blacks earn over a dollar more than sixteen year old whites and yet face unemployment rates that are 1.5 times higher. Another explanation for the differences in employment rates is differences in the variance of productivity. However, the binding on the minimum wage for sixteen year old whites is almost twice the binding rate for nineteen year old blacks. The data suggest that search may be an important explanation in the differences in black-white outcomes with firms more easily able to target their search based upon race than based upon age.

To ensure that the cross-race differences in labor market outcomes are not do to the small sample sizes in North Carolina, we repeat the analysis in Table 1 and 2 using data from all states in the south. In particular, we add to the data set Alabama, Arkansas, Delaware, the District of Columbia, Florida, Georgia, Kentucky, Louisiana, Maryland, Mississippi, Oklahoma, South Carolina, Texas, Tennessee, Virginia, and West Virginia. Table 3 replicates Table 1 for the states located in the south. The same trends emerge with black teenagers substantially more likely to come from single parent families and have parents with lower incomes than white teenagers. The one substantial difference between North Carolina and the rest of the south is that both the probability of searching and the probability of finding a job are higher in North Carolina despite the similarity in wages across the two groups. ${ }^{5}$

\footnotetext{
${ }^{5}$ This is suggestive that workers in North Carolina have less bargaining power but are
} 
Table 2: Sample Statistics for North Carolina by Age and Race

\begin{tabular}{llcccc}
\hline \hline & \multicolumn{5}{c}{ Age } \\
& & 16 & 17 & 18 & 19 \\
\hline \multirow{2}{*}{ Whites } & 0.386 & 0.501 & 0.558 & 0.606 \\
& $\operatorname{Pr}($ Search $)$ & 0.848 & 0.893 & 0.892 & 0.902 \\
& Hourly Wage $\mid$ Search $)$ & 5.56 & 5.78 & 6.31 & 7.06 \\
& & $0.794)$ & $(0.924)$ & $(1.38)$ & $(1.79)$ \\
& Observations & 1089 & 1114 & 976 & 725 \\
& & & & \\
& Pr(Search) & 0.209 & 0.329 & 0.432 & 0.502 \\
& $\operatorname{Pr}$ (Emp | Search) & 0.610 & 0.720 & 0.746 & 0.761 \\
& $\operatorname{Pr}$ (Min Wage Binds) & 0.293 & 0.257 & 0.208 & 0.093 \\
& Hourly Wage & 5.48 & 5.51 & 5.82 & 6.62 \\
& & $(0.710)$ & $(0.650)$ & $(0.989)$ & $(1.40)$ \\
& Observations & 393 & 359 & 301 & 258 \\
\hline
\end{tabular}

Table 4 replicates the age and race differences in employment outcomes from Table 2 for the south. The same patterns emerge: older workers fare better both in wages and in employment probabilities. Perhaps as a result, older workers are substantially more likely to search. The key feature suggesting a search model of the labor market remains: nineteen year old blacks earn substantially more than sixteen year old whites yet have are much less likely to be able to find employment.

negotiating over a larger surplus than workers in the rest of the south. See Ahn and Arcidiacono (2005) for a detailed discussion of identification of differences in bargaining power across states. 
Table 3: Sample Statistics for Southern States by Race

\begin{tabular}{lcccccc}
\hline \hline & \multicolumn{2}{c}{ Entire Sample } & \multicolumn{2}{c}{ Searching } & \multicolumn{2}{c}{ Employed } \\
& Black & White & Black & White & Black & White \\
\hline Age & 17.30 & 17.30 & 17.73 & 17.61 & 17.78 & 17.65 \\
& $(1.09)$ & $(1.08)$ & $(1.06)$ & $(1.07)$ & $(1.05)$ & $(1.06)$ \\
Weekly Parent Income (\$) & 570 & 849 & 571 & 826 & 605 & 842 \\
& $(439)$ & $(583)$ & $(427)$ & $(543)$ & $(441)$ & $(543)$ \\
Parent Income Not Reported & 0.036 & 0.139 & 0.036 & 0.120 & 0.042 & 0.125 \\
Parent Not Working & 0.203 & 0.082 & 0.165 & 0.062 & 0.126 & 0.052 \\
Female & 0.469 & 0.465 & 0.451 & 0.470 & 0.466 & 0.460 \\
Single Parent & 0.509 & 0.209 & 0.497 & 0.217 & 0.456 & 0.206 \\
Pr(Search) & 0.314 & 0.442 & & & & \\
Pr(Emp.|Search) & & & 0.659 & 0.838 & & \\
Hourly Wage & & & & & 5.93 & 6.10 \\
& & & & & & \\
\end{tabular}

\section{Empirical Specification}

In this section we show how to estimate the structural model. Estimation is similar to Ahn and Arcidiacono with the extension that firms now can partially target their search. The partial targeting of search occurs on the basis of age and race. Hence $K$ is the set of all possible age-race combinations.

Estimation has three components. First, for those individuals who successfully match we observe wages. Second, we need to estimate the parameters of the zero profit condition. Although we do not observe the probability of a firm finding a match, we are able to rewrite the zero profit condition as a function of the individual's probability of finding a match. Finally, we observe decisions 
Table 4: Sample Statistics for Southern States by Age and Race

\begin{tabular}{llcccc}
\hline \hline & \multicolumn{5}{c}{ Age } \\
& & 16 & 17 & 18 & 19 \\
\hline \multirow{2}{*}{ Whites } & $\operatorname{Pr}$ (Search) & 0.281 & 0.417 & 0.533 & 0.624 \\
& $\operatorname{Pr}($ Emp | Search) & 0.775 & 0.838 & 0.852 & 0.868 \\
& Hourly Wage & 5.59 & 5.72 & 6.19 & 6.70 \\
& & $.833)$ & $(.883)$ & $(1.41)$ & $(1.71)$ \\
& Observations & 10560 & 10085 & 8231 & 6515 \\
& & & & \\
& & & & & \\
Pr(Search) & 0.170 & 0.276 & 0.390 & 0.510 \\
& Pr(Emp | Search) & 0.574 & 0.653 & 0.663 & 0.708 \\
& Pr(Min Wage Binds) & 0.360 & 0.238 & 0.209 & 0.156 \\
& Hourly Wage & 5.48 & 5.61 & 5.92 & 6.38 \\
& & $(.740)$ & $(.800)$ & $(1.18)$ & $(1.51)$ \\
& Observations & 3223 & 3002 & 2453 & 2000 \\
\hline
\end{tabular}

by individuals as to whether to search. We can use these decisions to estimate the supply side parameters.

\subsection{Parameterizing Wages}

We assume that $\ln \left(S_{i j k}\right)$ is given by:

$$
\ln \left(S_{i j k}\right)=X_{i k} \theta+\epsilon_{i j}
$$

where $X_{i k}$ are characteristics of individual $i$ 's market and type ${ }^{6}$ and $\theta$ is the set of parameters to be estimated. We assume that the $\epsilon$ 's are drawn from one of two distributions, one $\mathrm{N}\left(\mu_{1}, \sigma_{1}\right)$ and the other $\mathrm{N}\left(\mu_{2}, \sigma_{2}\right)$. The probability of the draw coming from the $r$ th distribution is then given by $\pi_{r}$.

\footnotetext{
${ }^{6}$ As discussed in the data section, a market is defined at the age, race, state, month, and year level.
} 
Since the wage generating process is given by: $W_{i j k}=\max \{\beta S, \underline{W}\}$, without a minimum wage log wages would be given by:

$$
\ln \left(W_{i j k}\right)=X_{i k} \theta+\ln (\beta)+\epsilon_{i j}
$$

In the presence of a minimum wage the wage distribution is then distributed truncated log-normal with censoring at the minimum wage. The truncation occurs when the match value is so low that the firm rejects the match. This occurs whenever $\underline{W}>S_{i j k}$. There are then three relevant regions for the quality of the match:

$$
\begin{aligned}
\beta S_{i j k} \geq \underline{W} & \Rightarrow\left\{W_{i j k}=\beta S_{i j k}\right\} \\
S_{i j k} \geq \underline{W}>\beta S_{i j k} & \Rightarrow\left\{W_{i j k}=\underline{W}\right\} \\
\underline{W}>S_{i j k} & \Rightarrow\{\text { No match }\}
\end{aligned}
$$

We then observe successful matches for those who are employed either at or above the minimum wage. Let $N_{11 k}$ and $N_{12 k}$ indicate the number of individuals of type $k$ who have wage observations above and at the minimum wage respectively. The likelihood for these observations then follows:

$$
\begin{aligned}
\mathcal{L}_{1}= & \left(\prod_{k=1}^{K} \prod_{i=1}^{N_{11 k}} \frac{\sum_{r=1}^{2} \pi_{r} \phi\left(\frac{W_{i}-X_{i k} \theta-\ln (\beta)-\mu_{r}}{\sigma_{r}}\right) / \sigma_{r}}{\sum_{r=1}^{2} \pi_{r}\left(1-\Phi\left(\frac{\ln (\underline{W})-X_{i k} \theta-\mu_{r}}{\sigma_{r}}\right)\right)}\right) \times \\
& \left(\prod_{k=1}^{K} \prod_{i=1}^{N_{12 k}} \frac{\sum_{r=1}^{2} \pi_{r}\left(\Phi\left(\frac{\ln (\underline{W})-X_{i k} \theta-\ln (\beta)-\mu_{r}}{\sigma_{r}}\right)-\Phi\left(\frac{\ln (\underline{W})-X_{i k} \theta-\mu_{r}}{\sigma_{r}}\right)\right)}{\sum_{r=1}^{2} \pi_{r}\left(1-\Phi\left(\frac{\ln (\underline{W})-X_{i k} \theta-\mu_{r}}{\sigma_{r}}\right)\right)}\right)
\end{aligned}
$$

where $X_{i k}$ includes the characteristics of the market for the $i$ th individual. In particular, $X_{i k}$ includes age, race, quarter, ${ }^{7}$ and year indicator variables. $\Phi$ and $\phi$ are then the cdf and pdf of the standard normal distribution.

\subsection{Parameterizing Firms}

Although we have no information on the firm, we can infer the parameters of the profit function by rewriting the zero profit condition as a function of an

\footnotetext{
${ }^{7}$ Because we are using only non-summer months, quarter one is defined as December, January, and February, quarter as March, April, and May, and quarter three as September, October, November.
} 
individual's probability of finding a match. We first show that we can rewrite the zero profit condition as a function of $p_{m}$, the probability of a worker finding a match after being assigned to search method $m$, rather than as a function of $q_{m}$. Next, we show what the distributional assumptions imply for the expected values of $S$ and $W$ given that a match is acceptable. With these expressions and the expressions for $p_{m}$, we can then rewrite the expression with respect to what we actually observe in the data, $p_{k} \psi_{k}$, where $p_{k}$ is the probability that a worker of $k$ th type receives a match and $\psi_{k}$ is the probability that the match is successful.

The probability of finding a match for firms and workers who are assigned to market $m$ is given by:

$$
q_{m}=A\left(\frac{N_{m}}{J_{m}}\right)^{1-\alpha} \quad p_{m}=A\left(\frac{J_{m}}{N_{m}}\right)^{\alpha}
$$

implying that we can write $q_{m}$ as:

$$
q_{m}=A^{\frac{1}{\alpha}} p_{m}^{\frac{\alpha-1}{\alpha}}
$$

Substituting for $q_{m}$ as a function of $p_{m}$ in the zero profit condition yields:

$$
A^{\frac{1}{\alpha}} p_{m}^{\frac{\alpha-1}{\alpha}} E\left(\max \left\{S_{m}-W_{m}, 0\right\}\right)-C_{2}=0
$$

Solving for $p_{m}$ yields:

$$
p_{m}=\delta E\left(\max \left\{S_{m}-W_{m}, 0\right\}\right)^{\frac{\alpha}{1-\alpha}}
$$

where:

$$
\delta=C_{2}^{\frac{-\alpha}{1-\alpha}} A^{\frac{1}{1-\alpha}}
$$

We can now substitute for $E\left(\max \left\{S_{m}-W_{m}\right\}, 0\right)$ with the corresponding probabilities and expected values conditional on type:

$$
p_{m}=\delta\left(\sum_{k=1}^{K} \Lambda_{m k} E\left(\max \left\{S_{k}-W_{k}, 0\right\}\right)\right)^{\frac{\alpha-1}{\alpha}}
$$

We model the probability of begin assigned to a particular search method as following a multinomial logit process where $\lambda_{m k}$ is given by:

$$
\lambda_{m k}=\frac{\exp \left(Z_{k} \zeta_{m}\right)}{1+\sum_{m^{\prime}=2}^{M} \exp \left(Z_{k} \zeta_{m^{\prime}}\right)}
$$


withe $\lambda_{1 k}$ given by:

$$
\lambda_{1 k}=\frac{1}{1+\sum_{m^{\prime}=2}^{M} \exp \left(Z_{k} \zeta_{m^{\prime}}\right)}
$$

Given the assumed distribution of $S$ and the parameters of the wagegenerating process, we can calculate $E\left(\max \left\{S_{k}-W_{k}, 0\right\}\right)$, the expected surplus from matching with a particular worker type. This surplus can be broken down into three parts for each type of worker: 1) when the match value is high enough such that the minimum wage does not bind, $\left.\tilde{S}_{1 k}, 2\right)$ when the match value is such that the minimum wage binds, $\tilde{S}_{2 k}$, and 3 ) when the match value is so low that the firm rejects the match. The last of these parts yields an expected surplus of zero. The first and second parts are then given by:

$$
\begin{aligned}
\tilde{S}_{1 k}= & \sum_{r=1}^{2} \pi_{r}\left[\exp \left(X_{k} \theta+\ln (1-\beta)+\mu_{r}+\sigma_{r}^{2} / 2\right) \Phi\left(\frac{\sigma_{r}^{2}-\ln (\underline{W})+X_{k} \theta+\ln (\beta)+\mu_{r}}{\sigma_{r}}\right)\right] \\
\tilde{S}_{2 k}= & \sum_{r=1}^{2} \pi_{r}\left[\exp \left(X_{k} \theta+\mu_{r}+\sigma_{r}^{2} / 2\right) B_{r k}\right. \\
& \left.-\left(\Phi\left(\frac{\ln (\underline{W})-X_{k} \theta-\mu_{r}-\ln (\beta)}{\sigma_{r}}\right)-\Phi\left(\frac{\ln (\underline{W})-X_{k} \theta-\mu_{r}}{\sigma_{r}}\right)\right) \underline{W}\right]
\end{aligned}
$$

where:

$B_{r k}=\left(\Phi\left(\frac{\sigma_{r}^{2}-\ln (\underline{W})+X_{k} \theta+\mu_{r}}{\sigma_{r}}\right)-\Phi\left(\frac{\sigma_{r}^{2}-\ln (\underline{W})+X_{k} \theta+\ln (\beta)+\mu_{r}}{\sigma_{r}}\right)\right)$

We then define $\tilde{S}_{k}$ such that:

$$
\tilde{S}_{k}=E\left(\max \left\{S_{k}-W_{k}, 0\right\}\right)=\tilde{S}_{1 k}+\tilde{S}_{2 k}
$$

$p_{m}$ can then be rewritten as:

$$
p_{m}=\delta\left(\sum_{k=1}^{K} \Lambda_{m k} \tilde{S}_{k}\right)^{\frac{\alpha}{1-\alpha}}
$$

We do not observe $p_{m}$. Rather, we observe whether a black or a white worker obtains employment conditional on searching. Recall that the probability of an individual of the $k$ th type matching is:

$$
p_{k}=\sum_{m=1}^{M} \lambda_{m k} p_{m}
$$


What we observe in the data is $p_{k} \psi_{k}$ where $\psi_{k}$ gives the probability of a successful match conditional on matching:

$$
\psi_{k}=\sum_{r=1}^{2} \pi_{r}\left(1-\Phi\left(\frac{\ln \underline{W}-X_{k} \theta-\mu_{r}}{\sigma_{r}}\right)\right)
$$

Substituting in for the $p_{m}$ in the expression for $p_{k}$ and multiplying by $\psi_{k}$ yields:

$$
p_{k} \psi_{k}=\psi_{k} \sum_{m=1}^{M} \lambda_{m k} \delta\left(\sum_{k=1}^{K} \Lambda_{m k} \tilde{S}_{k}\right)^{\frac{\alpha}{1-\alpha}}
$$

Positive search outcomes for workers are then Bernoulli draws from $p_{k} \psi_{k}$. The likelihood function is then given by:

$\mathcal{L}_{2}=\prod_{k=1}^{K} \prod_{i=1}^{N_{2 k}}\left(\psi_{k} \sum_{m=1}^{M} \lambda_{m k} \delta\left(\sum_{k=1}^{K} \Lambda_{m k} \tilde{S}_{k}\right)^{\frac{\alpha}{1-\alpha}}\right)^{y_{i k}=1}\left(1-\psi_{k} \sum_{m=1}^{M} \lambda_{m k} \delta\left(\sum_{k=1}^{K} \Lambda_{m k} \tilde{S}_{k}\right)^{\frac{\alpha}{1-\alpha}}\right)^{y_{i k}=0}$

where $y_{i k}$ indicates whether or not the $i$ th worker was matched and $N_{2 k}$ is the number of searching workers of the $k$ th type.

Identification of $\beta$ separately from $\delta$ occurs because of the differences in the binding rates of the minimum wage and how these differences affect the corresponding probability of unemployment. If $\beta$ is close to one, then there will be few individuals whose productivity places them right at the minimum wage. Identification of $\alpha$ then come from how the surpluses relate back to the probabilities of matching: if there is a lot of variation in the surpluses with little variation in match probabilities then $\alpha$ must be small.

\subsection{Parameterizing the Individual}

We now turn to the decision by individuals as to whether or not to search. We can write the individual's decision to search as:

$$
p \psi\left(E(W)-R_{i}\right)-C_{1}>0 .
$$

where $\psi$ is the probability that the match value is high enogh to be acceptable conditional on matching. With the estimates from the previous two stages it is possible to calculate expected wages and the probability of employment for each 
individual. We now need to parameterize the reservation values. In particular, we parameterize $R_{i}$ such that all workers have positive reservation values:

$$
R_{i}=\exp \left(X_{i} \gamma+\epsilon_{i}\right)
$$

$X_{i}$ is then a vector of demographic characteristics which affect the individual's outside option, the $\gamma$ 's are the coefficients to be estimated, and $\epsilon_{i}$ is the unobserved portion of the reservation value.

Substituting in and solving for $\epsilon_{i}$ shows that an individual will search when:

$$
\epsilon_{i}<\log \left(E(W)-\frac{C_{1}}{p \psi}\right)-X_{i} \gamma
$$

We assume that the $\epsilon$ 's are distributed $\mathrm{N}\left(0, \sigma_{s}\right)$. Note that any coefficient on the $E(W)$ will become part of an intercept term in $X_{i}$ as it will be factored out due to the log. This will then change the interpretation of the cost of searching as it will be relative to a coefficient of one on expected wages. The variance term, not normally identified in a probit specification, is identified here. That is, to get us back to a probit, we normalize the $\epsilon$ 's to have a variance of one. Equation (12) then becomes:

$$
\tilde{\epsilon}_{i}<\frac{\log \left(E(W)-\frac{C_{1}}{p}\right)}{\sigma_{s}}-\frac{X_{i} \gamma}{\sigma_{s}}
$$

The coefficient on the log expression then gives one over the standard deviation of the $\epsilon$ 's. The smaller is $\sigma_{s}$ the more search is explained by differences in the labor market outcomes as opposed to preferences.

Since we do not observe the $\epsilon$ 's, the likelihood function is then given by:

$L_{3}=\prod_{i=1}^{N_{3}} F\left(\frac{\log \left(E(W)-\frac{C_{1}}{p \psi}\right)-X_{i} \gamma}{\sigma_{s}}\right)^{s_{i}=1}\left(1-F\left(\frac{\log \left(E(W)-\frac{C_{1}}{p \psi}\right)-X_{i} \gamma}{\sigma_{s}}\right)\right)^{s_{i}=0}$

where $N_{3}$ is the total number of potential searchers and $F$ is the standard normal cdf.

While it is possible to estimate all three stages simultaneously, the additive separability of the log likelihood function makes it possible to estimate the parameters in stages. In practice, we estimate the parameters of the wage 
generating process and of the zero profit condition jointly. Taking these parameters as given, we then estimate the parameters of individual's decision to search.

\section{Results}

Estimates of the wage generating process with the exception of the generalized Nash bargaining parameter, $\beta$, are given in Table 5 . Nineteen year olds generate surplus values twenty percent higher than sixteen year olds while blacks have surplus values that are almost nine percent lower than whites. ${ }^{8}$ Although the mixture distribution significantly improved the fit of the model, the difference in the means of the two distributions is small. However, the distribution with the smaller mean had a variance that was about a third of the variance of the distribution with the larger mean.

The parameters of the zero profit condition are given in Table 6 . These parameters are estimated jointly with the parameters of the wage distribution. The generalized Nash bargaining parameter, $\beta$, was close to 0.85 suggesting that the market for teenage workers is fairly competitive. $\alpha$, which measures how sensitive the matching function is to the number of searching firm versus the number of searching workers was about 0.26 . This is substantially lower than the standard in the macroeconomics literature of 0.5 (Petrongolo and Pissarides 2001).

Of more interest are the targeting parameters. Recall that these are logit parameters embedded in the zero profit condition. What these parameters imply is that firms are able to almost fully target their search by race with little targeting by age. With the exception of white sixteen year olds, all whites were assigned to one method with all blacks assigned to the other. White sixteen year olds were the only group mixed across the two methods with sixty-five percent of the time being assigned with the other white teenagers.

\footnotetext{
${ }^{8}$ Surplus values refer to the total surplus which would include any compensation the firm would take for not wanting to hire blacks.
} 
Table 5: Parameters of the Log Wage Regression

\begin{tabular}{|c|c|c|}
\hline Variable & Coefficient & Standard Error \\
\hline Age $=17$ & 0.031 & 0.010 \\
\hline Age $=18$ & 0.100 & 0.011 \\
\hline Age $=19$ & 0.207 & 0.014 \\
\hline Black & -0.088 & 0.011 \\
\hline 1990 & -0.002 & 0.016 \\
\hline 1991 & 0.009 & 0.016 \\
\hline 1992 & -0.022 & 0.016 \\
\hline 1993 & -0.009 & 0.016 \\
\hline 1994 & 0.000 & 0.015 \\
\hline 1995 & 0.010 & 0.015 \\
\hline 1996 & -0.013 & 0.020 \\
\hline 1997 & 0.069 & 0.017 \\
\hline 1998 & 0.071 & 0.018 \\
\hline 1999 & 0.103 & 0.020 \\
\hline 2000 & 0.113 & 0.020 \\
\hline Quarter 2 & -0.005 & 0.009 \\
\hline Quarter 3 & 0.028 & 0.009 \\
\hline$\mu_{1}$ & 1.649 & 0.015 \\
\hline$\sigma_{1}$ & 0.098 & 0.009 \\
\hline$\mu_{2}$ & 1.657 & 0.021 \\
\hline$\sigma_{2}$ & 0.271 & 0.013 \\
\hline$\pi_{2}$ & 0.571 & 0.053 \\
\hline
\end{tabular}

With the parameter estimates we can calculate the average probability of begin matched conditional on age and race. These forecasts are given in Table 7. We see that white teenagers above the age of sixteen have a $94.4 \%$ chance of matching with a firm. In contrast, a black teenager has $89.4 \%$ chance of 
Table 6: Parameters of the Zero Profit Condition

\begin{tabular}{llcc}
\hline \hline & Variable & Coefficient & Standard Error \\
\hline \multirow{3}{*}{ Search } & Age $=16$ & 0.509 & 1.481 \\
Targeting $=17$ & 10.331 & - \\
& Age $=18$ & 10.564 & - \\
& Age $=19$ & 11.768 & - \\
& Black & -21.423 & - \\
& & & \\
$\beta$ & 0.848 & 0.016 \\
$\delta$ & 0.944 & 0.056 \\
$\alpha$ & 0.256 & 0.073 \\
\hline
\end{tabular}

matching. Nineteen year olds are then penalized for being pooled with younger workers of the same race. This pooling does not bite too hard for whites as the match rates are so high.

Table 7 also shows the average probability that a match is successful, that is, has a surplus value at least at the level of the minimum wage, conditional on age and race. Here we see large differences across age and to some extent across race as well. Nineteen year old blacks are then primarily unemployed due to not matching with a firm while sixteen year old whites are primarily unemployed due to low surplus values once a match has been obtained.

The parameter estimates of the wage generating process and the zero profit condition are then used in the search decisions to form the probability of obtaining a successful match as well as the expected wage conditional on a successful match. These estimates are reported in Table 8. Search costs are significant and the estimate of the variance on preferences is small suggesting that labor market conditions are important in determining job search.

High family income increase one's reservation value leading to lower search probabilities. Reservation values for sixteen year olds are substantially higher 
Table 7: Predicted Match Probabilities by Age and Race

\begin{tabular}{llcccc}
\hline \hline & & 16 & 17 & 18 & 19 \\
\hline \multirow{2}{*}{ Whites } & $\operatorname{Pr}$ (Match) & 0.925 & 0.944 & 0.944 & 0.944 \\
& $\operatorname{Pr}$ (Success | Match) & 0.883 & 0.903 & 0.937 & 0.970 \\
& & & & & \\
Blacks & $\operatorname{Pr}$ (Match) & 0.894 & 0.894 & 0.894 & 0.894 \\
& $\operatorname{Pr}$ (Success | Match) & 0.792 & 0.831 & 0.891 & 0.944 \\
\hline
\end{tabular}

than for those older, with little difference between the ages of seventeen and nineteen. Blacks have higher reservation values while coming from a single parent family has no effect.

Since the parameters of a probit are difficult to interpret, in Table 9 we forecast how the probability of searching changes as we vary either labor market conditions or the demographics of searchers. Theses simulations take all other characteristics as given and vary the values of the relevant variables.

Changing expected wages leads to a labor supply elasticity of 1.8. Since higher expected wages will also lead to higher probabilities of finding a match, the total response to better labor market conditions would be even higher. Smaller effects are observed for family income. Increasing family income by $10 \%$ lowers labor force participation by $1 \%$.

Of particular interest are how difference in preferences and labor market conditions for blacks and whites drive the differences in search behavior. Recall that blacks are substantially less likely to search than whites. The estimates show that this difference is equally split between differences in preferences and differences in labor market conditions. Moving everyone's preferences from those of whites to those of blacks reduces labor participation by a little under 19\%. Changing expected wages and the probability of matching from those whites face to the labor market conditions black face lowers labor force participation by almost $17 \%$. 
Table 8: Parameter Estimates of the Utility Function

\begin{tabular}{|c|c|c|c|}
\hline & & Coefficient & Standard Error \\
\hline & $1 / \sigma_{s}$ & 1.854 & 0.565 \\
\hline & $C_{1}$ & 1.338 & 0.650 \\
\hline & Constant & 1.754 & 0.940 \\
\hline & Black & 0.232 & 0.106 \\
\hline & Single Parent & -0.002 & 0.047 \\
\hline Reservation & Weekly Family Income ( $\$ 000 ’ s)$ & 0.158 & 0.038 \\
\hline \multirow{18}{*}{ Values } & Father Employed, Missing Income & 0.293 & 0.061 \\
\hline & Parents Not Working & 0.265 & 0.073 \\
\hline & Age $=17$ & -0.236 & 0.060 \\
\hline & Age $=18$ & -0.266 & 0.115 \\
\hline & Age $=19$ & -0.204 & 0.206 \\
\hline & 1990 & 0.117 & 0.074 \\
\hline & 1991 & 0.150 & 0.080 \\
\hline & 1992 & 0.026 & 0.098 \\
\hline & 1993 & 0.046 & 0.086 \\
\hline & 1994 & -0.070 & 0.075 \\
\hline & 1995 & -0.042 & 0.075 \\
\hline & 1996 & -0.137 & 0.097 \\
\hline & 1997 & 0.095 & 0.113 \\
\hline & 1998 & 0.239 & 0.115 \\
\hline & 1999 & 0.426 & 0.143 \\
\hline & 2000 & 0.342 & 0.146 \\
\hline & Quarter 2 & -0.021 & 0.043 \\
\hline & Quarter 3 & 0.031 & 0.052 \\
\hline
\end{tabular}


Table 9: Changes in the Probability of Searching

\begin{tabular}{ll}
\hline \hline & Percent Change in \\
& Probability of Searching \\
\hline $10 \%$ change in Expected Wage & $17.9 \%$ \\
$10 \%$ change in Parental Income & $-1.1 \%$ \\
White to Black Preferences & $-18.8 \%$ \\
White Labor Market to Black Labor Market & $-16.9 \%$ \\
\hline
\end{tabular}

\section{Policy Simulations}

We focus our policy simulations on changing the degree to which firms can target on the basis of race. We treat the economy as all individuals in North Carolina data set and assume they face the labor market from 1995. Given the demographics and the parameter estimates, we first calculate for the equilibrium with targeting. This is accomplished by starting out with an initial guess as to the probabilities each worker will search. Given these probabilities, we calculate expected wages and the probability of matching. Given these expected wages and match probabilities, we then update the search probabilities and continue updating until convergence. The response to the change in policy is calculated in a similar manner. We assume that the parameters of the zero profit condition are the same as with targeting except that now firms can no longer target based upon age or race.

Table 10 shows the changes in the probabilities of searching and matching for blacks and whites with the removal of targeting. The removal of targeting lowers the equilibrium values of $S$ for white teenagers. However, recall that that firms were able to partially screen out white sixteen year olds. Hence, white sixteen year olds actually see increases in the probability of searching and matching. This is not the case for white teenagers who are older than sixteen. These teenagers faces small drops in the probability of matching which in turn leads to small drops in the probability of searching. Note that these drops have 
a reenforcing dimension. As nineteen year old whites drop out of the labor market, the expected surplus from a match from the firm's perspective falls. With falling expected surpluses, more teenagers will drop out.

The losses faced by white teenagers over sixteen are counterbalanced by the gains for black teenagers. Black teenagers see their probability of matching increase by almost four percent. Corresponding increases then occur in the probability that black teenagers search. The largest gains are seen for younger ages as there as more individuals in this group are at the margin of searching.

Table 10: Changes in Labor Market Outcomes with the Removal of Targeting

\begin{tabular}{lccccc}
\hline \hline & & 16 & 17 & 18 & 19 \\
Change in & Whites & $0.49 \%$ & $-0.77 \%$ & $-0.58 \%$ & $-0.43 \%$ \\
$\operatorname{Pr}($ Search) & Blacks & $5.69 \%$ & $4.10 \%$ & $2.75 \%$ & $1.89 \%$ \\
& & & & & \\
Change in & Whites & $0.61 \%$ & $-1.32 \%$ & $-1.32 \%$ & $-1.32 \%$ \\
$\operatorname{Pr}($ Match) & Blacks & $3.97 \%$ & $3.97 \%$ & $3.97 \%$ & $3.97 \%$ \\
\hline
\end{tabular}

\section{Conclusion}

Differences in labor market outcomes between blacks and whites are stark. Wage differences are small relative to differences in unemployment. In fact, nineteen year old blacks earn more than sixteen year old whites despite having higher unemployment rates. The effect of these unemployment rates is magnified by the resulting lower search rates for black teenagers.

We propose and structurally estimate a search model with endogenous labor demand and labor supply. Unemployment has two sources in the model. First, unemployment comes from workers not matching with firms. Second, those who do match may draw match values so low that firms are unwilling to pay these workers the minimum wage. Firms are able to partially target their search and we find that firms find it easier to target their search on the basis of race than 
on the basis of age. The primary reason for unemployment among nineteen year old blacks then comes from the low probability of matching with a firm. In contrast, the main reason for unemployment among sixteen year old whites are match values below the minimum wage.

Removing firm targeting decreases the black-white unemployment gap. In response to the higher employment rates, more blacks search. However, pooling black and white workers leads to higher unemployment for whites as blacks have on average lower surplus values. This has a reenforcing effect as whites respond to the higher unemployment rates by exiting the labor force.

\section{References}

[1] Ahn, Tom and Peter Arcidiacono, "Minimum Wages and Positive Employment Effects in General Equilibrium" Working Paper, Duke University, 2005

[2] Black, Dan A., "Discrimination in an Equilibrium Search Model" Journal of Labor Economics 13, (1995), 309-334

[3] Bowlus, Audra J. and Zvi Eckstein, "Discrimination and Skill Differences in an Equilibrium Search Model" International Economic Review 43, (2002) 1309-1345

[4] Cain, Glen G. and Ross E. Finnie, "The Black-White Difference in the Youth Employment: Evidence for Demand-Side Factors" Journal of Labor Economics 8, (1990), S364-S395

[5] Card, D. and A. B. Krueger, "Minimum Wage and Employment: A Case Study of the Fast-Food Industry in New Jersey and Pennsylvania." American Economic Review, 84, (1994) 772-793.

[6] Card, D. and A. B. Krueger, Myth and Measurement: The New Economics of the Minimum Wage. Princeton University Press, Princeton NJ., 1995. 
[7] Coate, S. and G. C. Loury, "Will Affirmative-Action Policies Eliminate Negative Stereotypes?" American Economic Review, 83, (1993), 1220-40

[8] Dickens, Richard and Alan Manning, "Spikes and Spill-Overs: The Impact of the National Minimum Wage on the Wage Distribution in a Low-Wage Sector" The Economic Journal, 114, 2004, C95-C101

[9] Eckstein, Zvi and G.B, van den Berg, "Empirical Labor Search: A Survey" Journal of Econometrics, forthcoming.

[10] Eckstein, Zvi and Kenneth I. Wolpin, "Estimating the Effect of Racial Discrimination on First Job Wage Offers" The Review of Economics and Statistics, 81, (1999) 384-392

[11] Flinn, Chris, "Minimum Wage Effects on Labor Market Outcomes under Search with Bargaining." Mimeo, New York University, (2003)

[12] Lang, K. and S. Kahn, "The Effect of Minimum-wage Laws on the Distribution of Employment: Theory and Evidence." Journal of Public Economics, 69, (1998), 67-82

[13] Lee, David S., "Wage Inequality in the United States During the 1980s: Rising Dispersion or Falling Minimum Wage?" The Quarterly Journal of Economics, 114 , (1999),977-1023

[14] Meyer, Robert H. and David A. Wise, "The Effects of the Minimum Wage on the Employment and Earnings of Youth" Journal of Labor Economics, 1, (1983a), 66-100

[15] Meyer, Robert H. and David A. Wise, "Discontinuous Distributions and Missing Persons: The Minimum Wage and Unemployed Youth" Econometrica, 51, (1983b), 1677-1698

[16] Neumark, D. and Wascher W. "Minimum Wages and Employment: A Case Study of the Fast-Food Industry in New Jersey and Pennsylvania: Comment." American Economic Review, 90, (2000) 1362-1396 
[17] Roy, A. D., "Some thoughts on the Distribution of Earnings," Oxford Economic Papers, 3, (1951), 135-146

[18] Petrongolo B. and Christopher Pissarides, "Looking in to the Black Box: A Survey of the Matching Function" Journal of Economics Literature, 39, (2001), 390-431

[19] Sattinger, Michael, "Statistical Discrimination with Employment Criteria" International Economic Review, 39, (1998) 206-236

[20] van den Berg, G.J. "Multiple Equilibria and Minimum Wages in Labor Markets with Informational Frictions and Heterogeneous Production Technologies" International Economic Review, 44, (2003), 1337-1359

[21] Welch, Finis, "The Employment of Black Men" Journal of Labor Economics, 8, (1990), S26-S74 